\title{
The use of Social Network Analysis in a study of intergroup relations between affirmative action and regular students in a public university
}

\section{O uso de Análise de Redes Sociais no estudo das relações intergrupais entre cotistas e não cotistas de uma universidade pública}

\author{
Elisa Maria Barbosa de Amorim RIBEIRO' ${ }^{1}$ (D) 0000-0002-4550-454X \\ Adriano de Lemos Alves PEIXOTO² (D) 0000-0003-1962-1571 \\ José Garcia Vivas MIRANDA ${ }^{3}$ (1) 0000-0002-7752-8319 \\ Antônio Virgílio Bittencourt BASTOS² (1) 0000-0002-1322-5749
}

\begin{abstract}
Higher education has joined affirmative action and promoted the coexistence between different social groups at universities. This study evaluated the interaction pattern between 926 affirmative action and regular students from 25 different undergraduate programs from a public university using an informal social networks questionnaire. Homophily was the parameter chosen to measure intergroup relations. This behavior was evaluated according to the student's term, yield rate (percentage of admitted students who enroll), field of knowledge and nature of relationship. The results showed a low degree of integration between groups in highly competitive undergraduate programs. The group of regular students showed a greater tendency for endogeneity. These results point to need to create a culture of inclusion that provides a distribution of resources between different social groups.
\end{abstract}

Keywords: Affirmative action; Education, higher; Social integration.

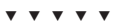

1 Universidade Salgado de Oliveira, Departamento de Psicologia, Programa de Pós-Graduação em Psicologia. R. Marechal Deodoro, 217, Bloco A, Centro, 24030-060, Niterói, RJ, Brasil. Correspondência para/Correspondence to: E.M.B.A. RIBEIRO. E-mail: <ribeiro. emba@gmail.com>.

2 Universidade Federal da Bahia, Instituto de Psicologia, Programa de Pós-Graduação em Psicologia. Salvador, BA, Brasil.

${ }^{3}$ Universidade Federal da Bahia, Instituto de Física, Departamento de Geofísica Nuclear. Salvador, BA, Brasil.

Support: Proufba encomenda: Pense, Pesquise e Inove a UFBA (edital 2014). This study was financed in part by the Coordenação de Aperfeiçoamento de Pessoal de Nivel Superior - Finance Code 001.

Article based on the doctoral dissertation of E.M.B.A. RIBEIRO, intitled "Análise de redes sociais e relações intergrupais: a convivência entre cotistas e não cotistas e suas influências na formação acadêmica". Universidade Federal da Bahia, 2015.

$\checkmark \nabla \boldsymbol{v}$

Como citar este artigo/How to cite this article

Ribeiro, E. M. B. A., Peixoto, A. L. A., Miranda, J. G. V., \& Bastos, A. V. B. (2019). The use of Social Network Analysis in a study of intergroup relations between affirmative action and regular students in a public university. Estudos de Psicologia (Campinas), 36, el70167. http://dx.doi.org/10.1590/1982-0275201936e170167 


\section{Resumo}

A adesão ao sistema de cotas no ensino superior promoveu a convivência entre grupos sociais distintos. O estudo avaliou o padrão de interação entre 926 estudantes cotistas e não cotistas de 25 turmas de uma universidade pública brasileira, utilizando um questionário de redes sociais informais. Homofilia foi o parâmetro escolhido para medir as relações intergrupais. Esse comportamento foi avaliado de acordo com o semestre, a concorrência, a área de conhecimento e a natureza da relação. Os resultados demonstraram baixo grau de integração entre os grupos nos cursos de alta concorrência, bem como maior tendência à endogenia no grupo de não cotistas. Tais resultados apontam a necessidade de se criar uma cultura inclusiva, que propicie a distribuição de recursos entre os diferentes grupos sociais envolvidos.

Palavras-chave: Ação afirmativa; Educação superior; Integração social.

Contexts of diversity have been increasingly promoted by public and business policies in response to the demands of social movements for the immediate inclusion of minority groups in privileged social spaces (Feres Júnior \& Daflon, 2014; Nóbrega, Santos, \& Jesus, 2014). Studies have indicated some unfavorable consequences arising from the coexistence among different social groups. In the workplace, for example, Guillaume, Dawson, Woods, Sacramento, and West (2013) listed consequences such as discrimination, interpersonal conflicts, absenteeism, and low commitment and performance. In the educational context, Sowell (2004) analyzed the impact of affirmative action in five countries and identified the presence of intergroup conflicts, as well as very few effective benefits for the social groups involved.

Despite the negative consequences, Duffy, Mowatt, Fuchs, and Salisbury (2014) highlight that educational institutions play an important role for the integration of different groups creating opportunities for the consolidation of a democratic society. Based on this ideal, the authors outline guidelines to help educational institutions adopt strategies to deal with diversity.

Research on the benefits or costs resulting from relations among actors from different groups has been the focus of Social Network Analysis (SNA) (Hewstone, 2015). This is an interdisciplinary field of study that investigates the interaction between social actors as a unit of analysis and emphasizes the identification, visualization and interpretation of the relationships among actors (Burt, Kilduff, \& Tasselli, 2013; Wölfer \& Hewstone, 2017). In the study of intergroup relations, the notion of homophily is used to evaluate the tendency to establish relations among actors with similar attributes (Centola, 2015; Lewis, 2015). Although it is considered a 'natural' tendency, the predominance of homogeneous patterns expresses intergroup disputes for recognition and social power. Some factors such as inequality in the distribution of resources and the role of institutions contribute to the reproduction of inequality (Lamont, 2014; Wimmer, 2013; Wimmer \& Lewis, 2011).

McPherson, Smith-Lovin, and Cook (2001) also discuss how patterns of homophily define hierarchical status between groups. After analyzing the panorama of studies in homophily, the authors concluded that homophily by race and ethnicity are the ones that promote the most intense social divisions in the interpersonal environment. The authors highlight associations between different positions in groups and dimensions such as occupation, religion, education and income. Wimmer and Lewis (2011) have equated the importance of homophily by income in the formation of homogeneous ties to homophily by race. In general, in accordance with SNA, the link between homophily and social status can be recognized in the network by the distance between members of different groups (Fu et al., 2016). The distance delimits boundaries between social categories and the actors are limited to the dynamics circumscribed by this social ecology (McPherson et al., 2001).

In social psychology, the theory of social identity is the main explanatory framework for the dynamics of intra- and intergroup relations. According to this theory, social identity is the consciousness of belonging to a group and affection generated by belonging to it. Cognitively, individuals place themselves and others 2 in groups as a strategy to understand and predict the behavior of others (Hogg, Abrams, \& Brewer, 2017). 
This so-called social categorization mechanism promotes a perceptual bias, making the intragroup similarities more salient and demarcating the differences with outside groups. This process may lead to disputes of prestige and status, especially in a context of competition (Hogg et al., 2017).

In the context of higher education, the affirmative action system in Brazil sanctioned by Law $n^{\circ} 12,711$ (Ministério da Educação, 2012) established a context of diversity associated with changes in university admission rules, which had previously been based on competitiveness and merit. This situation promoted the coexistence between groups from different economic, educational and cultural backgrounds as well as the inclusion of admission rules that were not agreed upon by both groups. A large part of the university community (administrators, professors, staff and students) had not dealt with these social groups before the affirmative action policy, except in less competitive undergraduate programs. Attending a university had not considered a life or work project for these groups before places set aside for affirmative actions.

Studies on the coexistence between different social groups are common in the American educational system. The emphasis of these studies rests on the tendency towards homophily by race, gender and age at different educational levels (Lozares, Verd, Cruz, \& Barranco, 2014; Smith, McPherson, \& Smith-Lovin, 2014). Recent studies, such as Wimmer and Lewis (2011), have pointed to other possible influential factors in the network homogeneity. These studies analyzed the Facebook networks of 1,640 students from a university in the United States. The results indicated that other types of homophily, such as coming from elite schools, are just as important as racial homophily. In addition to these aspects, processes of racial selection, reciprocal bonding and proximity (for example, sharing the same room) also increase the formation of homogeneous racial ties (Hanneman \& Riddle, 2005; Wimmer \& Lewis, 2011).

Although studies of homophily in American educational institutions are common, only one study in Brazil uses homophily in social networks to assess the relationship among university students. The study was carried out by Peixoto, Ribeiro, and Brito (2015) and they mapped the friendship networks of 94 first, third and fifth semester students of Psychology. The students reported who they regarded as their friends in a questionnaire. The results indicated high homophily in the networks, especially in first and third semester students. Although homophily decreased in the fifth semester, the group of regular students still maintained a high tendency for endogeneity, that is, to associate predominantly with each other.

Motivated by the results of the study by Peixoto et al. (2015), the present study expands the investigation of the degree of integration between affirmative action and regular students covering more fields of knowledge and types of links analyzed. The aim of this study was to evaluate the homophily behavior of affirmative action students from a federal public university according to the yield rate, semester, field of knowledge and nature of ties (friendship, information, gap and rejection).

\section{Method}

A total of 926 first, third and fifth semester students from nine highly competitive and less competitive undergraduate programs from five different fields of knowledge participated in the study. Based on these criteria, the selected undergraduate programs were as follows: Law and Pedagogy, Mechanical and Chemical Engineering, Medicine and Pharmacy, Modern Languages, Design and Arts.

The students were invited to answer a social network mapping questionnaire in which they were asked to name classmates they: 1) consider their friends (by 'friends' we mean colleagues with whom the student has more rapport); 2) ask for information on course tasks; 3) have no contact with, but would like to have; 4) have no contact with and would not want to have. These lead questions correspond respectively to the networks of friendship, information, gap and rejection. Friendship and information networks characterize positive links and existing relationships. The gap network represents hypothetical positive relations and rejection represents hypothetical negative relations. A total of 93 networks were mapped and distributed as follows: 25 friendship networks, 25 information networks, 23 gap networks and 20 rejection networks. 
A total of 1,178 students comprise the networks, since the 926 respondents could mention any colleague from their class, even though they were absent on the day of the data collection.

The research project was approved by the Nursing Ethics Committee of the Universidade Federal da Bahia on October 1, 2014 ( $\left.n^{\circ} 815,585\right)$. Study participants were informed of the purpose of the study and signed an informed consent form.

As for data analysis, the types of network surveyed, the semester (cross-section) and the field of knowledge served as the basis for exploring different cut-offs of groups of affirmative action and regular students, mainly in the descriptive comparisons (median, mean, standard), correlations and analyses of variance. The type of university admission, affirmative action system or free competition, was the variable used to distribute the students into two groups: affirmative action and regular students.

The measure used to analyze intergroup relations was the E-I index (Krackhardt \& Stern, 1988) that assesses the proportion of ties between members from different groups and members from the same group. This indicator ranges from -1 to +1 , with negative values indicating homophily and positive values indicating heterophily (relationship among different group members). The measure of significance of the general E-I index indicates whether there is a difference between it and the expected El. This allows the networks to be compared even though they have different group sizes. The E-I index measures were entered into the database as variables.

The $\mathrm{E}-\mathrm{I}$ Index data are non-parametric $(\mathrm{D}(100)=0.52, p<0.001)$. They were compared using descriptive statistics (mean and standard deviation), correlation (Spearman) and analysis of variance. Mann-Whitney's test was used to compare the two groups, the friendship and information networks, and the Kolmogorov-Smirnov test was used to compare the gap and rejection networks (with less than 25 cases).

\section{Results}

The more general question of the study refers to the degree of integration between affirmative action and regular students according to the type of tie investigated (friendship, information, gap or rejection). As a first step to answer it, simple frequency method was used to calculate the presence of homophily or heterophily in each class. Figure 1 shows the percentage of frequencies found in each type of tie. To build the figure, we considered homophily in the network if the value of the E-I index was $<-0.05$ and the presence of heterophily if the E-I index was $>0.05$. It is noteworthy that all the E-I indexes of the networks were significant, that is, they differed from the expected ones in relation to the proportion of the subgroups in the network. The means were extracted from the three semesters and the five fields of knowledge.

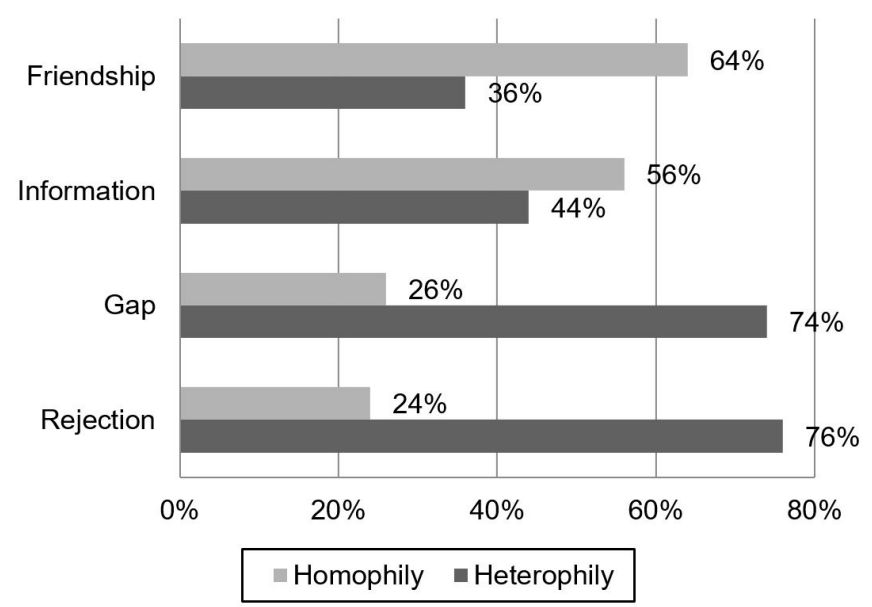

4 Figure 1. Frequency of the presence of homophily or heterophily in the classes for each type of tie in \%. 
Friendship networks are those with the highest presence of homophily (64\%), indicating that there is low interaction between affirmative action and regular students in the classes studied. This trend also appears in the information networks (56\%), although with a lower discrepancy between the number of groups that presented homophily or heterophily. This data can also be seen in the distribution of the percentiles (Table 1), in which $75 \%$ of the E-I index values are below -0.08 .

Most of the gap networks (74\%) present high heterophily. This indicates that affirmative action and regular students express the desire to establish relationships with students from the other group. Heterophily also appears in the rejection networks (76\%), but since these predict negative ties, the data on heterophily should be interpreted as rejection of those who are different. This means that the students stated that they do not have and do not want to establish relationships with certain colleagues belonging to the outside subgroup.

The frequent presence of heterophily in the networks of gap and rejection may denote a contradiction, since it would simultaneously indicate desire for the different other and rejection of those who are different. But these networks are different in their macro-structural characteristics, as the rejection networks are smaller and less dense that the gap networks. In addition, the variability of the indices of E-I index (Table 1) also presents significant differences, such as the presence of higher and more frequent heterophily indices in the gap network when compared to the rejection network. Given these differences, one hypothesis for future studies would be that there is a desire for greater integration between the groups, but rejection of specific actors who mostly belong to the exogroup.

To provide a closer view of the variability of the general E-I index in the networks, Table 1 shows the descriptive statistics of the E-I index of the 93 networks for each type of tie. The percentiles and maximum and minimum points reveal that students displayed a high degree of heterophily (between 0.5 and 1), but the greater concentration is in the E-I index below 0.03. In general, we can observe that the friendship networks have a more homogeneous distribution when compared with the others. On the other hand, the information and gap networks present great variability in all the parameters observed, such as the highest standard deviation values and distance between maximum and minimum points. Although the rejection networks present high standard deviation, variability is smaller when compared with the information and gap networks. Differences in the distribution of data by type of tie indicate the influence of the nature of the relationship on the patterns of intergroup relations.

To understand these differences, other analyses, such as the visualization of the E-I index distribution evaluated for the affirmative action and regular student subgroups, are required. This evaluation allowed us to identify whether the tendency to associate with different individuals (heterophily) or similar ones (homophily) was concentrated in one of the subgroups. Figure 2 shows the E-I index distribution graph for affirmative action and regular students for each type of tie. The observation reveals a greater tendency of regular students to establish relationships between similar ones when compared with the affirmative action students. This difference appears in all types of networks, being more evident in the networks of friendship, information and gap. In this last one, the behavior of affirmative action students is more homogeneous and with predominant tendency for heterophily in 19 of the 24 networks investigated.

Table 1

Means of the E-I index by type of tie

\begin{tabular}{lccccccccc}
\hline \multirow{2}{*}{ Tie } & \multirow{2}{*}{ Minimum } & \multirow{2}{*}{ Maximum } & \multirow{2}{*}{ Median } & \multirow{2}{*}{ Mean } & Standard & \multicolumn{4}{c}{ Percentile } \\
\cline { 7 - 10 } & & & & & & Deviation & 25 & 50 & 75 \\
\hline Friendship & -0.426 & 0.228 & -0.069 & -0.068 & 0.168 & -0.199 & -0.069 & 0.077 \\
Information & -0.355 & 1.000 & -0.088 & -0.031 & 0.285 & -0.241 & -0.088 & 0.111 \\
Gap & -0.538 & 1.000 & 0.034 & 0.094 & 0.273 & -0.180 & 0.034 & 0.189 \\
Rejection & -0.333 & 0.667 & 0.000 & 0.075 & 0.260 & -0.032 & 0.000 & 0.266 \\
\hline
\end{tabular}




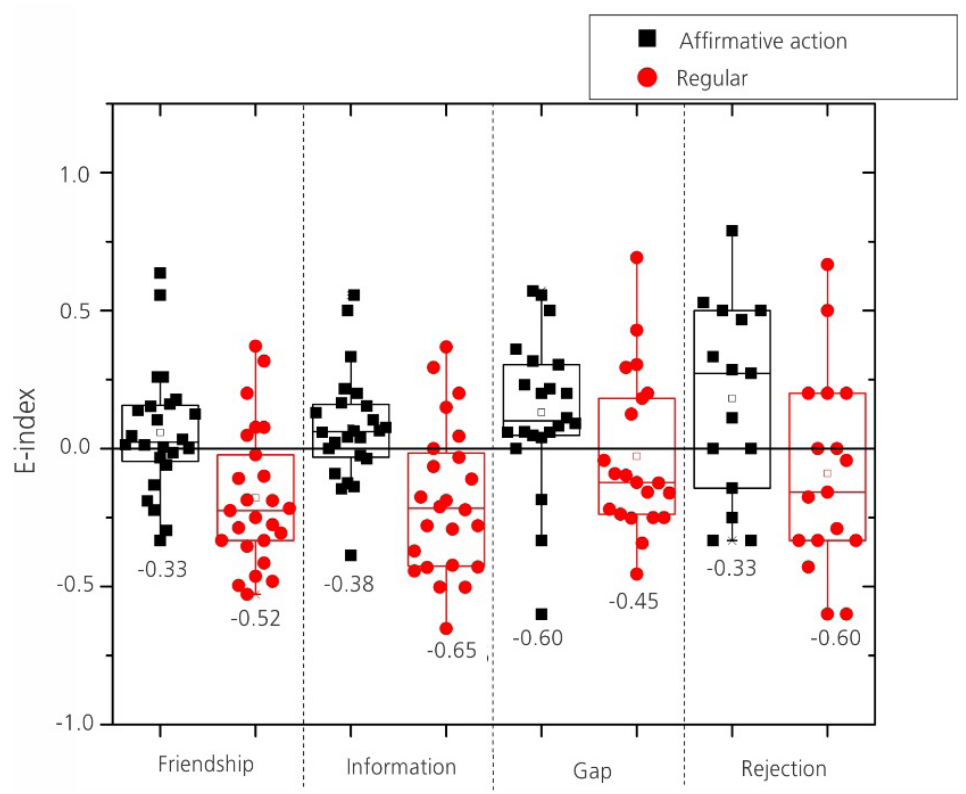

Figure 2. Boxplot of distribution of E-I index points of affirmative action and regular students by type of tie.

Another data shown in Figure 2 are the minimum values of the E-I index that show the subgroups with greater homophily among the mapped networks. In the friendship network, the highest degree of homophily ( $\mathrm{E}-\mathrm{I}=-0.528)$ was found among third semester affirmative action law students. In the information network, the highest index $(E-I=-0.652)$ was among first semester mechanical engineering students. The lack of integration between affirmative action and regular students in highly competitive undergraduate programs draws attention to the need to evaluate the relationship between these variables (E-I index and yield rate). This evaluation was one of the objectives of the study and it is discussed within this section. Regarding the minimum indexes of the $\mathrm{E}-\mathrm{I}$ index in the gap network, greater homophily $(\mathrm{E}-\mathrm{I}=-0.6)$ was found among third semester pedagogy students. This was the only network in which the highest homophily index was found in the subgroup of affirmative action students (Figure 2). The highest index for regular students was found in the same class $(E-I=0.455)$.

The rejection network was characterized by a negative tie. Homophily, in this case, indicates rejection from similar ones $(\mathrm{E}-\mathrm{I}=-0.333)$ and it was more significant among the affirmative action students from the first semester course in Design. In the regular student group, greatest homophily was observed in first semester students in the mechanical engineering course. The indices between 0 and 1 indicate rejection of those who are different, and higher indices were distributed in the different fields of knowledge studied and in all the semesters surveyed. The absence of a pattern may be related to the specificity of the tie studied, a nonexistent and undesired tie. The nature of the tie, along with the structural peculiarities of the rejection networks (reduced size and density) indicate the need for a specific study plan to understand the relationships between rejection ties and intergroup relations.

After analyzing the distribution profiles and identifying the undergraduate programs and semesters with the most critical indexes for homophily, the indexes were evaluated by the type of network and subgroup studied (Table 2). Following the previous tendency of the distribution, affirmative action students presented lower means when compared with regular students. The gap and rejection networks presented heterophily, but in the gap network the means of the two groups were similar. As for the rejection network, the affirmative action students have a greater tendency for heterophily (rejecting different ones). 
Comparison of E-I index of affirmative action and regular students in each type of tie

\begin{tabular}{|c|c|c|c|c|c|c|}
\hline Tie & Group & Median & Mean & Standard Deviation & U /K-S & $r$ \\
\hline \multirow{2}{*}{ Friendship } & Affirmative action & 0.03 & 0.10 & 0.29 & \multirow{2}{*}{$144 * * *$} & \multirow{2}{*}{0.65} \\
\hline & Regular & -0.23 & -0.18 & 0.25 & & \\
\hline \multirow{2}{*}{ Information } & Affirmative action & 0.06 & 0.11 & 0.27 & \multirow{2}{*}{$145 * * *$} & \multirow{2}{*}{0.65} \\
\hline & Regular & -0.21 & -0.14 & 0.35 & & \\
\hline \multirow{2}{*}{ Gap } & Affirmative action & 0.11 & 0.17 & 0.32 & \multirow{2}{*}{$1.838 * *$} & \multirow{2}{*}{0.35} \\
\hline & Regular & -0.10 & 0.06 & 0.40 & & \\
\hline \multirow{2}{*}{ Rejection } & Affirmative action & 0.40 & 0.38 & 0.47 & 1.265 & \multirow{2}{*}{0.46} \\
\hline & Regular & -0.02 & 0.07 & 0.51 & $(p>0.08)$ & \\
\hline
\end{tabular}

Note: ${ }^{* *} p<0.01 ; * * * p<0.001$

The Mann-Whitney and Kolmogorov-Smirnov tests (Field, Miles, \& Field, 2012) were used to evaluate differences between the means of the groups of affirmative action and regular students. The data (Table 2) reveal that there was a significant difference between the E-I means of the two groups in all networks, except for the rejection network: friendship $(U=144, p<0.001)$; information $(U=145, p<0.001)$; gap $(\mathrm{K}-\mathrm{S}=1.838 p<0.002)$; rejection $(\mathrm{K}-\mathrm{S}=1.265, p>0.08)$.

So far, the network analysis of the classes has evidenced the predominance of homophily behavior in the friendship and information networks. When this behavior was observed from the standpoint of the subgroups of affirmative action and regular students, it was evident that the subgroup of regular students tended to associate with each other when compared with the affirmative action students.

In view of the variables that comprise the research scope, the homophily behavior was also evaluated according to the (highly and less) competitive undergraduate programs with the semesters surveyed (first, third and fifth) and, finally, with the fields of knowledge. For the first evaluation of the yield rate variable, tests on the differences between highly and less competitive undergraduate programs were carried out regarding the E-I index distribution. The differences between the groups were significant only for the friendship and information networks: friendship $(U=29, p<0.01)$; information $(U=21, p<0.01)$; gap $(\mathrm{K}-\mathrm{S}=0.52, p>0.05, r=)$; rejection (K-S =0.68, $p>0.05)$.

Based on the differences in behavior of the E-I index in the highly and less competitive courses, the correlation between the E-I index and yield rate was evaluated. The correlation measure was evaluated comparing the different types of network and the two subgroups studied (affirmative action and regular students). In the information network there was a negative and significant correlation between the E-I index and yield rate ( $r s=-, 524$, ps $<0.05)$, that is, the higher the yield rate, the lower the E-I index. In other words, the higher the yield rate, the greater is the tendency for endogeneity in the groups surveyed. There was a negative correlation, but not significant ( $r s=-, 391$, ps $>0.05$ ), in the friendship network. In the other networks, the correlations had a weak negative but a non- significant correlation.

In view of the lowest correlations found in the gap and rejection networks, the correlations between the two groups (affirmative action and regular students) and the first two networks (friendship and information) were compared. The negative correlation between yield rate and the E-I index appears in the two subgroups, but it is larger and significant in the subgroup of regular students ( $r s=-, 547, \mathrm{ps}<0.01$ ) when compared with the subgroup of affirmative action students ( $r s=-114, p s)$. 05).

The E-I index distribution separated by subgroup according to highly or less competitive undergraduate programs, as shown in Figure 3, expresses the tendency of the correlations observed. In the highly competitive programs for regular students, all E-I index points are negative, evidencing a high homophily behavior. When we observe the behavior of the E-I index for less competitive programs, distribution is more similar between affirmative action and regular students when compared with highly competitive programs. 


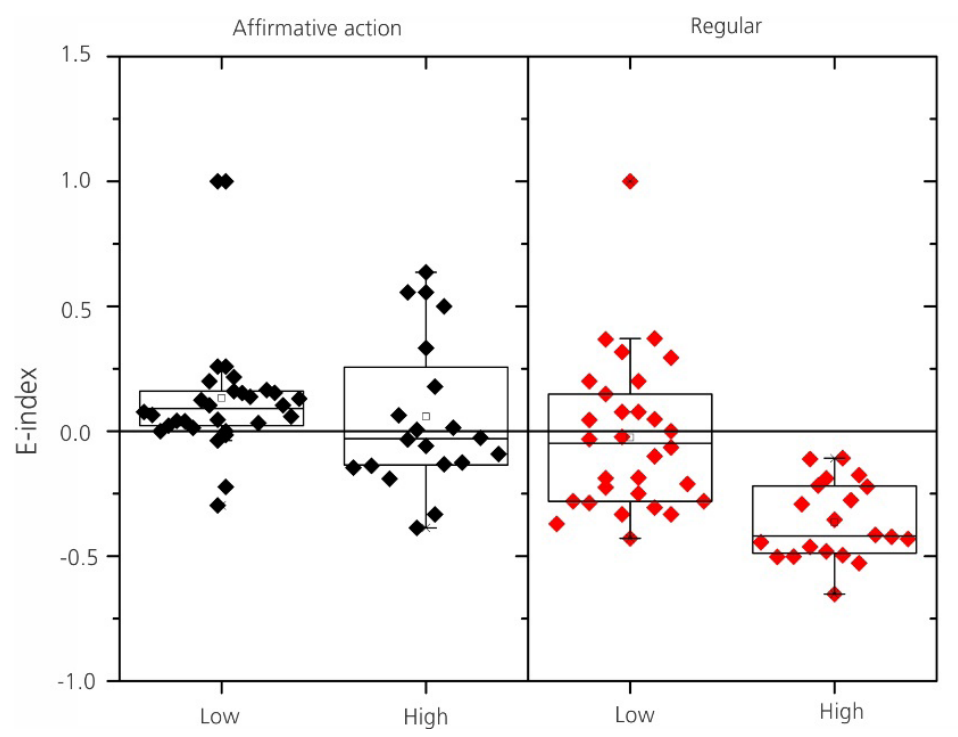

Figure 3. Distribution of E-I index points of affirmative action and regular subgroups according to highly and less competitive undergraduate programs.

With regard to the semester surveyed, with the exception of the gap network, the lowest means were found in the first semester and they increase over the semesters. At first, this means that there is a downward trend in homophily from the first to the fifth semester. However, the differences found in the behavior of the general E-I index for the three semesters surveyed were not significant: friendship $(H(2)=2.07, p>0.05)$; information $(H(2)=1.97, p>0.05)$; gap $(H(2)=2.79, p>0.05)$; and rejection $(H(2)=2.43, p>0.05)$. Following the same trend, the tests of differences between groups considering the five fields of knowledge were also not significant: friendship $(H(4)=4.27, p>0.05)$; information $(H(4)=4.20, p>0.05)$; gap $(H(4)=2.95, p>0.05)$; and rejection $(H(4)=2.15, p>0.05)$. In this sense, the semester variables and field of knowledge did not influence the degree of interaction between affirmative action and regular students.

\section{Discussion}

The results found in this study showed a low degree of integration between affirmative action and regular students in highly competitive programs studied (except Design). In addition, when the indices of each subgroup were observed, the affirmative action subgroup showed greater decomposition, in terms of SNA, or greater endogeny, in the terms of social psychology. These results confirm and expand the conclusions of Peixoto et al. (2015).

The finding of yield rate as an influential variable in the endogeneity of the groups became feasible by expanding the scope to include courses from all fields, grouped into highly and less competitive programs. Before the implementation of the affirmative actions, diagnostic studies on the portion of the population excluded from higher education indicated that this gap was more concentrated in highly competitive programs (Santos \& Queiroz, 2013). Despite places set aside for affirmative action students, demand analysis studies on admissions showed that affirmative action students were seeking less competitive programs, evidencing a behavior of self-selection (Cunha, 2006).

The admission of minority groups in highly competitive programs has placed very different groups in the same space. Differences are not restricted to school origin, but to other social hierarchy attributes such as income, cultural background, and ethnicity. The distance in the network between affirmative action and 
regular students has direct implications on access to available social capital within this structure. Among the ties studied, the information network specifically dealt with the relations established with the purpose of obtaining information about the course tasks. This network showed the strongest correlation between homophily and yield rate in the general index, as well as in the E-I index in the subgroup of affirmative action students. This pattern of interaction can be due to the mechanisms of favoritism triggered by competition among groups. These mechanisms are controlled by access to information and resources available in the network. As observed in the organizational context (Borgatti \& Foster, 2003), university homophily may play the role of reifying inequality and maintaining minorities isolated, even though they have been 'accepted' into higher education.

Even after more than 10 years of the establishment of the affirmative action system, the low integration between affirmative action and regular students makes us question the role of higher education within this scenario. Although access to the university has been possible through places set aside for affirmative action students, the admission process of affirmative action university students is still to come. More precisely, the role of the institution for the management of diversity, creation of an organizational culture favorable to those who are different and the distribution of resources among the social categories involved must be still considered.

Although the conceptual discussions about homophily consider it an expected phenomenon, it is necessary to reflect on how the low integration between the affirmative action and regular groups may be dysfunctional for university experience. As the presence of homophily has been identified in most of the courses studied, further studies should investigate the consequences of this network configuration for academic performance and experience.

\section{Contributors}

The authors equally contributed to all the stages of article preparation, namely: conception, design, analysis, interpretation of data, discussion of results, revision and approval of the final version of the article.

\section{References}

Borgatti, S. P., \& Foster, P. C. (2003). The network paradigm in organizational research: A review and typology. Journal of Management, 29(6), 991-1013.

Burt, R. S., Kilduff, M., \& Tasselli, S. (2013). Social network analysis: Foundations and frontiers on advantage. Annual Review of Psychology, 64(1), 527-547. http://dx.doi.org/10.1146/annurev-psych-113011-143828

Centola, D. (2015). The social origins of networks and diffusion. American Journal of Sociology, 120(5), 1295-1338. http://dx.doi.org/10.1086/681275

Cunha, E. M. P. (2006). Sistema universal e sistema de cotas para negros na Universidade de Brasília: um estudo de desempenho (Dissertação de mestrado não-publicada). Universidade de Brasília.

Duffy, L. N., Mowatt, R. A., Fuchs, M., \& Salisbury, M. A. (2014). Making diversity tangible: Assessing the role of servicelearning in teaching diversity. The International Journal of Critical Pedagogy, 5(2), 54-75. Retrieved May 3, 2015, from http://libjournal.uncg.edu/ijcp/article/view/546/654

Feres Júnior, J., \& Daflon, V. T. (2014). Políticas da igualdade racial no ensino superior. Cadernos do Desenvolvimento Fluminense, (5), 31-44. http://dx.doi.org/10.12957/cdf.2014.14229

Field, A., Miles, J., \& Field, Z. (2012). Discovering statistics using R. London: Sage Publications.

Fu, H., Xie, X., Rui, Y., Lian, D., Sun, G., \& Chen, E. (2016). Predicting social status via social networks: A case study on university, occupation, and region. Retrieved March, 30, 2017, from https://arxiv.org/pdf/1604.02694.pdf

Guillaume, Y. R., Dawson, J. F., Woods, S. A., Sacramento, C. A., \& West, M. A. (2013). Getting diversity at work to work: What we know and what we still don't know. Journal of Occupational and Organizational Psychology, 86(2), 123-141. http://dx.doi.org/10.1177/1368430217690909 
Hanneman, R. A., \& Riddle, M. (2005). Introduction to social network methods. Riverside: University of California.

Hewstone, M. (2015). Consequences of diversity for social cohesion and prejudice: The missing dimension of intergroup contact. Journal of Social Issues, 71(2), 417-438.

Hogg, M. A., Abrams, D., \& Brewer, M. B. (2017). Social identity: The role of self in group processes and intergroup relations. Group Processes \& Intergroup Relations, 20(5), 570-581. http://dx.doi.org/10.1177/1368430217690909

Krackhardt, D., \& Stern, R. N. (1988). Informal networks and organizational crises: An experimental simulation. Social Psychology Quarterly, 51(2), 123-140. Retrieved October 20, 2011, from http://www.jstor.org/stable/2786835

Lamont, M. (2014). Reflections inspired by ethnic boundary making: Institutions, power, networks by Andreas Wimmer. Ethnic and Racial Studies, 37(5), 814-819. http://dx.doi.org/10.1080/01419870.2013.871312

Lewis, K. (2015). How networks form: Homophily, opportunity, and balance. In R. A. Scott, S. M. Kosslyn, \& M. C. Buchmann (Eds.), Emerging trends in the social and behavioral sciences: An interdisciplinary, searchable, and linkable resource. New York: John Wiley \& Sons. http://dx.doi.org/10.1002/9781118900772.etrds0164

Lozares, C., Verd, J. M., Cruz, I., \& Barranco, O. (2014). Homophily and heterophily in personal networks: From mutual acquaintance to relationship intensity. Quality \& Quantity, 48(5), 2657-2670. http://dx.doi.org/10.1007/s11135-0139915-4

McPherson, M., Smith-Lovin, L., \& Cook, J. M. (2001). Birds of a feather: Homophily in social networks. Annual Review of Sociology, 27, 415-444.

Ministério da Educação (Brasil). (2012). Lei n 12.711/2012, de 29 de agosto de 2012. Novo Código Civil Brasileiro. Recuperado em outubro 20, 2013, de http://www.planalto.gov.br/ccivil_03/_ato2011-2014/2012/lei//12711.htm

Nóbrega, B. A., Santos, J. N., \& Jesus, G. A. (2014). Um estudo da relação entre diversidade, criatividade e competitividade em organizações brasileiras. Revista de Ciências da Administração, 16(39), 194-209. http://dx.doi.org/10.5007/21758077.2014v16n39p194

Peixoto, A. L. A., Ribeiro, E. M. B. A., \& Brito, F. S. (2015). A diversidade nos grupos sob o enfoque da análise de redes sociais. In A. V. B. Bastos, H. P. Regis, \& E. Loiola (Orgs.), Análise de redes sociais em contextos organizacionais (pp.505-520). Salvador: EDUFBA.

Santos, J. T., \& Queiroz, D. M. (2013). O impacto das cotas na Universidade Federal da Bahia (2004-2012). In J. T. Santos (Org.), O impacto das cotas nas universidades brasileiras (2004-2012) (pp.37-65). Salvador: Centro de Estudos AfroOrientais.

Smith, J. A., McPherson, M., \& Smith-Lovin, L. (2014). Social distance in the United States: Sex, race, religion, age, and education homophily among confidants, 1985 to 2004. American Sociological Review, 79(3), 432-456. http://dx.doi. org/10.1177/0003122414531776

Sowell, T. (2004). Affirmative action around the world: An empirical study. New Haven: Yale University Press.

Wimmer, A. (2013). Ethnic boundary making: Institutions, power, networks. Oxford: Oxford University Press.

Wimmer, A., \& Lewis, K. (2011). Beyond and below racial homophily: ERG models of a friendship network documented on Facebook. American Journal of Sociology, 116(2), 583-642. http://dx.doi.org/abs/10.1086/653658

Wölfer, R., \& Hewstone, M. (2017). Beyond the dyadic perspective: 10 reasons for using social network analysis in intergroup contact research. British Journal of Social Psychology. http://dx.doi.org/10.1111/bjso.12195

Received: December 5, 2017

Final version: September 11, 2018

Approved: October 30, 2018 